\title{
Múltiplas infecções oportunistas em um paciente com leucemia linfocítica crôníca tratado com cladribina
}

Erich V. de Paula ${ }^{1}$

Katia B.B. Pagnano ${ }^{1}$

Cármino A. de Souza ${ }^{1}$

Leandro Freitas ${ }^{2}$

Izilda Cardinalli ${ }^{2}$

Plínio Trabasso ${ }^{3}$

Irene Lorand-Metze ${ }^{1}$
Imunodeficiência humoral é uma característica intrínseca da leucemia linfocítica crônica B. A quimioterapia, principalmentequando o pacienteé politratado, eem especial os análogos da purina, ampliam o espectro de suscepti bilidade destes pacien tes a agentes infecciosos oportun istas devido ao efeito imunossupressor celular destas drogas. Relatamos um pacien te com leucemia linfocítica crônica submetido a várias linhas de quimioterapia, inclusive o 2-CdA, que apresentou múltiplas complicações infecciosas associadas a grave imunodeficiência celular.

Rev.bras.hematol.hemoter., 2000, 22(3): 420-423

Palavras-chave: Leucemia linfocítica crônica, neurocriptococose, cladribina

\section{Introdução}

A leucemia linfocítica crônica (LLC) é uma doença linfoproliferativa clonal de apresentação heterogênea, variando desde 0 achado fortuito de linfocitose isolada no sangue periférico, até quadros com grandes massas tumorais, e sinais de insuficiência medular grave. É a leucemia crônica mais comum. A idade mediana de diagnóstico é 65 anos, sendo rara em menores de 40 anos. A LLC está ainda associada a distúrbios do sistema imunológico que se manifestam na forma de fenômenos autoimunes, e de uma maior susceptibilidade a infecções, decorrente de uma deficiência humoral (hipogamaglobulinemia) inerente à própria doença.
Assim como sua apresentação, a sobrevida de pacientes com LLC pode variar. Estes fatos, acompanhados da incapacidade do tratamento convencional em alterar a história natural da doença, além de sua potencial toxicidade, fazem com que o mesmo seja em geral postergado até 0 aparecimento de complicações como citopenias graves, sintomas $B$, visceromegalias sintomáticas, grandes linfonodomegalias ou fenômenos autoimunes. Os sistemas de estadiamento mais utilizados contemplam o grau de falência medular e a massa tumoral mensurável, e permitem a estratificação dos pacientes em três categorias prognósticas. No entanto, dada a relevância da decisão de quando se deve iniciar o tratamento, outros fatores

1 - Disciplina de Hematologia do Departamento de Clínica Médica e Hemocentro da Unicamp

2 - Departamento de Anatomia Patológica da Faculdade de Ciências Médicas da Unicamp

3 - Disciplina de Moléstias Infecciosas do Departamento de Clínica Médica da Unicamp.

Correspondência para: Irene Lorand-Meze

Hemocentro - UNICAMP

Caixa Postal 6198 - Barão Geraldo. Campinas - São Paulo. CEP: 13081-970

Fone: (19) 788-8740 - Fax: (19) 788-8600

E-mail: ilmetze@unicamp.br 
prognósticos são de grande importância, principalmente para aqueles pacientes que se encaixam nos estadios de risco intermediário. Entre os mais importantes, podemos citar o tempo de duplicação linfocitária, os métodos de avaliação da proporção de células em ciclo celular proliferativo e parâmetros séricos como a dosagem de beta-2-microglobulina e da proteína CD23 solúvel (1).

A droga de escolha para o tratamento da LLC é o clorambucil, mas recentemente foram introduzidos como opção terapêutica, em especial para casos refratários aos esquemas baseados em agentes alquilantes, os análogos da purina, entre os quais a Cladribina (2-CdA).

\section{Relato do caso}

O paciente de 33 anos, sexo masculino, auxiliar de criação de suínos na zona rural do interior de São Paulo, iniciou acompanhamento na disciplina de Hematologia da Unicamp em março de 1997 com história de nove meses de linfonodomegalia de crescimento lento, perda de $12 \mathrm{Kg}$, febre e sudorese noturnas. Apresentava na ocasião linfonodos palpáveis de 1 a $4 \mathrm{~cm}$ de diâmetro, coalescentes, em cadeias cervicais, submandibulares, axilares, epitrocleares e inguinais, e linfocitose de $43 \times 10^{9}$ / I, sem alteração das outras séries. Imunofenotipagem: linfócitos positivos para CD5/ CD20, CD 19, CD23, com imunoglobulina de superfície monoclonal (cadeia kappa), compatível com o diagnóstico de LLC, estadio Binet B. À ultrassonografia apresentava esplenomegalia discreta, e linfonodomegalia intra-abdominal. Biópsia de medula óssea com infiltração focal paratrabecular e intersticial por LLC. Gamaglobulina sérica ao diagnóstico: $0,85 \mathrm{~g} / \mathrm{dl}$.

o paciente realizou oito ciclos de quimioterapia com clorambucil e prednisona, obtendo redução estimada em $50 \%$ da adenomegalia e manutenção da linfocitose, seguido por cinco ciclos de 2-CdA $(0,14 \mathrm{mg} /$ $\mathrm{Kg}$ por cinco dias a cada 28 dias), ao final dos quais apresentava redução estimada de $90 \%$ da adenomegalia, com 10.900 linfócitos/ $\mathrm{mm}^{3}$. Na ocasião, contagem de linfócitos T CD3/CD 4 era $73 / \mathrm{mm}^{3}$. o paciente se manteve bem por seis meses, evoluindo então com mialgia generalizada, cefaléia occipital e febres diárias.

Apresentava rigidez de nuca e monilíase oral. A punção do líquor demonstrou infecção por Criptococos neoformans. Iniciado Anfotericina $B$ até a negativação da cultura do LCR (dose total de 1.025 mg, aumentada até $2.900 \mathrm{mg}$ após recidiva da meningite), passandose então à manutenção com fluconazol 400 mg $\mathrm{VO} /$ dia. Na mesma época apresentou so rologia (IgM) e PCR positivo para CMV, tendo recebido Ganciclovir por 30 dias.

Nos meses subseqüentes apresentou ainda quadro de varicela, complicado por pneumonite intersticial e piora do quadro hematológico com plaquetopenia grave (menor que $10 \times 10^{9} / \mathrm{l}$ ) e anemia $(\mathrm{Hb}=8 \mathrm{~g} / \mathrm{dl})$. Em vista da progressão da doença e da evidente deterioração do quadro clínico do paciente, foi optado pelo início de CHOP-Bleo, tendo o paciente evoluído no fim do primeiro ciclo com quadro de sepse por Staphilococcus aureus multiresistente na vigência de neutropenia e óbito no $21^{\circ}$ dia pósquimioterapia.

\section{Achados de necrópsia}

Medula óssea intensamente hipocelular com infiltração remanescente por LLC. Infiltração por LLC também em linfonodos, fígado e epicárdio. O fígado apresentava numerosas colônias bacterianas. Esplenomegalia intensa com congestão e focos de necrose coagulativa. Pulmões congestos, com alvéolos preenchidos por hemácias e células inflamatórias. Nódulos subpleurais e em parênquima pulmonar com necrose caseosa central e células gigantes tipo Langhans, com bacilos álcool-ácido resistentes e colônias bacterianas. Espessamento meníngeo com abundantes macrófagos contendo corpos estranhos arredondados que não se coraram para fungos. Rins aumentados de tamanho com necrose tubular aguda.

\section{Discussão}

Deficiência imune e autoimunidade são características intrínsecas da LLC-B. A imunodeficiência é caracterizada por uma 
hipogamaglobulinemia progressiva, que piora com a evolução doença, eventualmente associada a um grau de imunodeficiência celular (2). Assim, estes pacientes apresentam uma maior susceptibilidade a infecções graves, mais comumente bactérias que necessitam opsonização (Pneumococo, Haemophilus,etc.). No presente caso, a gamaglobulina sérica já se encontrava no limite inferior ao diagnóstico, e diminuiu ainda mais após a quimioterapia.

O 2-CdA é uma droga que foi inicialmente desenvolvida como imunossupressor. Seu mecanismo de ação baseia-se em sua conversão intracelular em CdATP, molécula cujo acúmulo progressivo leva a um desequilíbrio nos pools de desoxiribonucleotídeos, bloqueando os mecanismos de reparo do DNA, e levando a um acúmulo de fitas simples de DNA que iniciam o processo de apoptose dos linfócitos. Embora, em geral, a toxicidade limitante para seu uso seja o efeito mielossupressor, no caso relatado foi seu efeito imunossupressor o mais relevante para o curso do paciente.

0 efeito imunossupressor do 2-CdA é intenso e prolongado (5). O número de linfócitos totais cai após sete dias - sendo relatado em alguns casos até a síndrome da lise tumoral - com queda acentuada dos linfócitos $T$, especialmente os CD4+. O corre ainda 0 desaparecimento dos monócitos com normalização em alguns meses. A mediana de recuperação dos níveis de linfócitos T CD4+ pode ocorrer em até 24 meses, e a dos CD8+ em torno de três meses, resultando na queda da relação CD4/CD8.

Desta forma, o uso de análogos da purina amplia o espectro de susceptibilidade a infecções, mesmo na ausência de neutropenia ou uso de corticoesteróides, passando a incluir agentes oportunistas entre os quais Candida sp., Pneumocistis carinii e o vírus varicella zoster são os mais freqüentes (3). Entre os fatores de risco independentes associados a uma maior incidência de infecções após o uso do 2-CdA foram identificados 0 uso prévio de quimioterapia, estadios III e IV de Rai, e o aumento de creatinina (4). Infecções atípicas foram mais comuns em pacientes com LLC e naqueles que fizeram o uso concomitante de corticoesteróides.
O caso relatado mostra a ocorrência rara da LLC em um paciente com menos de 40 anos. Tanto os fatores de risco, quanto a relação entre a sobrevida esperada e a observada, não diferem entre pacientes acima e abaixo de 50 anos (5). No entanto, em pacientes mais jovens a diferença entre a sobrevida esperada e a observada consiste em um período bastante longo, fato que pode suscitar uma maior reflexão sobre o planejamento terapêutico. No caso descrito, a decisão pelo início do tratamento se deveu à existência, também incomum, de febre, sudorese noturna e emagrecimento, com impacto importante no estado geral do paciente. Além disso, o tempo de duplicação linfocitária foi menor que 12 meses. De acordo com os estadiamento de Binet, o paciente foi estratificado para uma categoria intermediária de risco. É precisamente nestes casos que a disponibilização de outros indicadores de prognóstico se torna fundamental para uma melhor abordagem terapêutica (1).

O curso clínico após o uso da Cladribina ilustra o aumento da susceptibilidade a infecções, englobando agentes típicos e atípicos. A neurocriptococose é infecção comum em paciente com SIDA, tendo sido descrita por Ikpeazu et al.(6) após o uso da Cladribina em tricoleucemia. Van Den Neste et al. (7) demostraram ainda que infecções por vírus do grupo Herpes tais como citomegalovírus e varicela zoster ocorrem com freqüência significativamente maior em pacientes tratados com a Cladribina. 0 evento final do caso foi o de uma sepse num período de neutropenia após o uso do CHOP-bleo. No presente caso, as sucessivas quimioterapias, principalmente do 2$\mathrm{CdA}$, aumentaram e ampliaram cumulativamente a imunossupressão neste paciente (hipogamaglobulinemia e diminuição dos linfócitos T).

Finalmente, o achado de necrópsia de tuberculose pulmonar ativa consiste no segundo caso documentado em nosso serviço (dados não publicados) desta infecção em pacientes tratados com a Cladribina. Recentemente, Broady et al. (8) descreveram a associação de micobacteriose atípica e 2-CdA em um paciente com tricoleucemia, tendo a associação do uso de Fludarabina e tuberculose já sido descrita por Montserrat et al. (9). 
Several opportunistic infections in a young patient with chronic lymphocytic leukemia treated with cladribine

Erich V. de Paula, Katia B.B. Pagnano, Cármino A. de Souza, Leandro Freitas, Izilda Cardinalli, Plínio Trabasso, Irene Lorand-Metze

\section{Summary}

Hypogamaglobulinemia is frequently associated with B-CLL rendering the patients proneto bacterial infections. The use of purine analogs that cause depletion of T lymphocytes in the treatment of this disease, increases the spectrum of susceptibility of these patients to oportunistic agents. We report a case of a young B-CLL patient treated with 2-CdA, who presented multiple infectious complications during the course of his disease associated with a severe cellular immune deficiency.

Rev.bras.hematol.hemoter.,2000,22(3):420-423

Key words: Chronic lymphocityc leukemia, cryptococcal meningitis, cladribine

\section{Referências Bibliográficas}

1. Lorand-Metze I. Leucemias Iinfoides crônicas. Diagnóstico, estadiamento, fatores prognósticos e tratamento. Ser. Monogr. Esc. Bras. Hematol. 1999; 6; 18-22.

2. Keating M.J. Translational research in chronic lymphocytic leukemia. American Society of Hematology 1999; 249-54.
3. Cheson B.D. Infectiousand immunossupressive complications of purineanalog therapy. J Clin Oncol 1995; 12(9): 2431-48.

4. O'Brien S. Infectious Complications of Nucleoside Analogs. American Society of Hematology 1999; 536-42.

5. Mauro F.R., Foa R., Giannarelli D., Cordone I. et al. Clinical characteristics and outcome of young chronic lymphocytic leukemia patients: a single institution study of 204 cases. Blood 1999; 94(2); 448-54.

6. Ikpeazu E.V., Kaplon M. Cryptococcal meningitis occurring at 19 months after cladribine therapy for hairy cell leukemia.

Eur J Haematol 1998; 61(4): 286-7.

7. Van Den Neste E. , Delannoy A., Vandercam B. et al. Infectious complications after 2chlorodeoxyadenosine therapy. Eur J Haematol 1996; 56: 235-40.

8. Broady R., Roberts S., Hawkins T. Mycobacterium avium-intracellularecomplex infection following 2-cholodeoxyaden osine therapy for hairy cell leukemia. Leuk Lymphoma 2000; 36: 639-42.

9. Montserrat E., Lopez-Lorenzo J.L., Manso F. et al. Fludarabine in resistant or relapsing B-cell chronic lymphocitic leukemia. The spanish group experience. Leuk Lymphoma 1996; 21: 467.

Recebido: 06/07/2000

Aceito: $13 / 10 / 2000$ 